\title{
Structural Perspective on Molecular Interaction of IgG and IgA with Spike and Envelope Proteins of SARS-CoV- 2 and Its Implications to Non-Specific Immunity
}

\author{
Mohammad Kalim Ahmad Khan ${ }^{1}{ }^{(D)}$, Nutan Babasaheb Pokharkar ${ }^{2}$ (D), Fahad M. Al-Khodairy ${ }^{3}$ (D) Feras \\ M. Al-Marshad 4 (iD), Jamal M. Arif 5,*iD
}

1 Department of Bioengineering, Integral University, Lucknow-226026, Uttar Pradesh, India; mkakhan@iul.ac.in (K.M.K.A.);

2 Rajiv Gandhi medical college, Kalwa, Thane-400605, Maharashtra, India; nutan77p@ gmail.com (P.N.B.);

3 King Faisal Specialist Hospital and Research Center, Riyad, KSA; khodairy@kfshrc.edu.sa (A.K.F.M.);

4 Department of Internal Medicine, College of Medicine, Shaqra University, Shaqra, 11961, KSA; falmarshad@ su.edu.sa (A.M.F.M.);

5 Department of Biochemistry, College of Medicine, Shaqra University, Shaqra, 11961, KSA; jmarif@ su.edu.sa (J.M.A.);

* Correspondence: jmarif@ su.edu.sa;

Received: 8.10.2020; Revised: 9.11.2020; Accepted: 11.11.2020; Published: 15.11.2020

\begin{abstract}
Severe acute respiratory syndrome coronavirus 2 (SARS-CoV-2), a ruthless killer of the human population and highly transmissible, has become a big threat to public health by spreading one of the most infectious coronavirus diseases (COVID-19). Vaccine production is of paramount importance at present, albeit it is a gradual and time taking process. Since the predicament demand is immediate prevention, we hypothesized the utility of $\operatorname{IgG} 2$ a LA5 and IgA antibodies developed inside the body after vaccination to assess its protective effects as non-specific immunity against SARS-CoV2. Identifying the vaccine for repurposing, we considered the C-terminal domain of spike protein (S1CTD) and envelope (E) protein for molecular interactions with aforesaid antibodies using computational and Bioinformatics tools in order to elucidate its practicality and applicability. Our in silico findings exhibited the involvement of S1-CTD and E-protein hotspot residues as key players in molecular interaction with IgG2a LA5 and IgA and exhibited better binding efficiency (higher negative $\Delta \mathrm{G}$ and lower $K_{d}$ values) in comparison to their cognate host receptors (ACE2 and MPP5). Detailed hotspot residue analysis of S1-CTD and E-protein with IgG2a LA5 and IgA indicates that the existing vaccine could be used as a preventive measure against SARS-CoV-2.
\end{abstract}

Keywords: SARS-CoV-2; COVID-19; IgG2a LA5; IgA; ACE2; MPP5.

(C) 2020 by the authors. This article is an open-access article distributed under the terms and conditions of the Creative Commons Attribution (CC BY) license (https://creativecommons.org/licenses/by/4.0/).

\section{Introduction}

The recent outbreak of the severe acute respiratory syndrome coronavirus 2 (SARSCoV-2), previously known by the provisional name 2019 novel coronavirus (2019-nCoV), in the city of Wuhan in China's Hubei province in 2019-2020 has been causing significant numbers of mortality and morbidity in humans with the coronavirus infection disease (COVID19) showing fever, severe respiratory illness, and pneumonia [1]. The exponential growth of COVID-19 cases throughout the world has put tremendous pressure on the scientific fraternity to discover and produce preventive and effective treatments in a short span of time. With over 22,000 publications and >2000 ongoing clinical trials for vaccine and/or oral antiviral drugs, 
they show tireless efforts to develop effective therapy against SARS-CoV-2 infection [2]. Moreover, identification and complete annotation of about 56 proteins cognate to humans and SARS-CoV-2 facilitate extra edge on its underlying infection mechanism [3].

Deciphering and distributing a promising vaccine to enhance the immunity of billions of people worldwide due to the relatively high rate of infection caused by intensive SARSCoV-2 and subsequent mortality is highly desirable at the earliest. This has led to unprecedented scientific collaborations and the exchange of scientific information worldwide among the leading pharmaceutical industries and research laboratories to achieve the common goal of procuring an effective vaccine at the earliest. In this context, various developing vaccines seem to produce non-specific immune effects apart from showing pathogenic specificity.

Further, a lot of curiosity has also been seen in looking retrospectively at the already developed antiviral drugs and vaccines for their effectiveness against the SARS-CoV-2 [4-10]. The presently available live attenuated vaccines viz., smallpox vaccine, Bacillus CalmetteGuérin (BCG), Measles, and oral Poliovirus vaccine (OPV) also induce non-specific effects on the immune system [11-13]. It may be noted that various immunological mechanisms mediating non-specific effects include the induction of protective immune response and clonal expansion of lymphocytes against non-self pathogens, thereby boosting the innate immunity via inheritable changes and metabolic adaptability [14].

SARS-CoV-2, one of the seventh coronaviruses known to spread disease in human, is basically a cytoplasmic replicating pathogen with positive-polarity, single-stranded RNA (ssRNA) genome, structurally consists of four major membrane-bound proteins viz., spike (S), envelope (E), and membrane $(\mathrm{M})$ and nucleocapsid $(\mathrm{N})$ glycoproteins along with few subsidiary proteins $[15,16]$. Virus entry into the host cells is mediated through interactions between spike (S) glycoprotein, a homotrimer, and angiotensin-converting enzyme 2 (ACE2). S-protein consists of two domains $\mathrm{S} 1$ and $\mathrm{S} 2$, in which $\mathrm{S} 1$ contains the N-terminal domain (NTD) and C-terminal domain (CTD), collectively known as receptor binding site. Severe acute respiratory syndrome coronavirus (SARS-CoV) and Middle East respiratory syndrome coronavirus (MERS-CoV) previously used S1-CTD as a receptor-binding domain (RBD). At the same time, S1-NTD interacts with its cognate receptor in mouse hepatitis coronavirus. However, identifying the exact receptor binding site of SARS-CoV-2 with its host receptor ACE2 is underway [17-19].

Notwithstanding targeted vaccine pursuit, clinical assessment of non-specific vaccines, e.g., BCG against COVID-19 in some countries like Australia and The Netherlands, is underway. The logic behind this pursuance was a comparison of deaths occurring in countries getting a predominant neonatal vaccination exhibited lower incidence as compared to the countries lacking deep-rooted vaccination [7]. It is well established through pre-clinical and clinical studies that the BCG vaccine exhibited non-specific immune response; however, due to lack of experimental proof and clinical relevance of its protective effect against COVID-19 WHO does not recommend it [8-10].

Since all viral pathogens use some cellular receptors to enter the host cell, it is imperative to explore the receptor interaction site for virulence susceptibility. Being a vital part of pathogen-host entry gateway and cellular adapter building blocks, the glycoproteins have been gaining high momentum towards designing immunotherapeutics and prophylactic vaccines against COVID-19. However, the traditional route of vaccine development taking between 5-10 years correspondingly put forth a formidable challenge. Nonetheless, great 
strides have been made by the Coalition for Epidemic Preparedness Innovations (CEPI) and GAVI, the Vaccine Alliance, to take the challenge in a coordinated fashion in financing, development, production, and distribution of vaccines for SARS-CoV-2 [5,6,20].

In the light of scientific data supporting non-specific protective immunity, it is highly desirable to look into the common interface residues of viral glycoproteins and host receptor molecules. Subsequent identification of the pathogen's interacting residues at the interface of their cognate neutralizing antibodies of host developed upon exposure of past infection seems to establish the most probable structural insight into the underlying mechanism of non-specific immunity. This study considers two antibodies (Abs) IgG2a LA5, and IgA for molecular interaction studies with SARS-CoV-2 S-and E-glycoproteins through molecular docking simulation. Identified residues at the interface of S1-CTD protein and the most plausible binding site of E-protein with aforesaid Abs shed light on the elucidation of viral pathogenesis at the structural level and predict important clues for the establishment of underlying nonspecific defense mechanisms.

\section{Materials and Methods}

\subsection{Structure retrieval of viral and cellular proteins.}

3D structure of S1-CTD protein co-crystallized with host receptor ACE2 (PDB ID: 6LZG) [15], Fragment antigen-binding (Fab) domain of IgG2a LA5 (PDB ID: 4EBQ) [21], Fab fragment of IgA (5KW9) [22], and MPP5 (https://covid19.uniprot.org/uniprotkb/Q8N3R9) a cellular interactant of E-protein (PDB ID: 4UU5) [23] were retrieved from research collaboratory for structural bioinformatics (RCSB) protein data bank (PDB) Due to the unavailability of E-protein 3D structure in RCSB PDB, we checked it through Zhang Lab at University of Michigan (https://zhanglab.ccmb.med.umich.edu/COVID19/), and Swiss model repository (SMR) where they predicted its structure using I-Tasser tool and Swiss model server (https://covid-19.uniprot.org/uniprotkb/P0DTC4), respectively.

\subsection{E-protein model evaluation and validation.}

We evaluated and validated the predicted model of E-protein through PROCHECK [24], Qualitative Energy ANalysis (QMEAN) [25], and Protein quality prediction (ProQ) [26] tools. The PROCHECK tool checks the stereochemical quality of the model by analyzing residue-by-residue geometry and overall structure geometry, QMEAN evaluates to structure in terms of Global Score. In contrast, ProQ tool uses Levitt- Gerstein (LG) and Maximum Substructure (MaxSub) score [27, 28].

\subsection{Protein preparation and optimization.}

PDB and predicted structure of viral and cellular proteins were prepared as inputs for molecular docking through removing undesired heteroatoms, ions, and molecules. The CHARMm force field was assigned to them and carried out two steps of energy minimization to remove the bad steric clashes using steepest descent and conjugate gradient algorithm for 1000 steps at an RMS gradient of 0.01 and 0.05, respectively [29]. 


\subsection{Computational simulation.}

We used Hex 8.0.0 [30], ZDOCK [31], ClusPro [32, 33], and Patchdock [34] tools for rigid protein docking, and HADDOCK for flexible protein docking [35]. The Hex 8.0.0 tool uses a spherical polar Fourier (SPF) algorithm along with rotational correlations [36], an improved version of the traditional fast Fourier transform (FFT) scoring function. The ZDOCK produces the top 10 docking models on the basis of shape complementarity, desolvation, and electrostatic energy terms [37]. The ClusPro implies FFT correlation integrating a multistage protocol like-rigid body docking, energy-based filtering, ranking the retained structures based on clustering properties, and finally yields best models with minimum energy and large clusters size [38]. The PatchDock relies on a shape complementarity-based geometry algorithm along with an atomic desolvation energy term followed by the removal of redundant decoys through clustering of root mean square deviation (RMSD) [39]. The HADDOCK deals with flexible protein docking based on various energy terms (van der Waals energy, electrostatic energy, desolvation energy, and restraint violation energy), HADDOCK score, cluster size, Z-score, and buried surface area [40].

\subsection{Binding affinity prediction.}

In the case of flexible protein docking, the binding propensity of all docking interactants was evaluated through various HADDOCK parameters [40]. PROtein binDIng enerGY (PRODIGY) server was used to analyze the molecular interaction tendency and stability for both flexible and rigid docking in terms of binding affinity $(\Delta \mathrm{G})$ and dissociation constant $\left(\mathrm{K}_{\mathrm{d}}\right)$ $[41,42]$. Docked complexes have the least RMSD, and greater binding affinity was taken forward for further docking analysis.

\subsection{Visualization of docked complexes.}

The surface structure and interacting residues of docked complexes were visualized using CHIMERA, developed at the University of California, San Francisco (UCSF), and DIMPLOT of LigPlot $^{+}$respectively [43, 44]. The DIMPLOT uses 3D coordinates of interacting molecules and generates 2D schematic diagrams wherein dashed lines and arcs exhibiting H-bonds and hydrophobic interactions, respectively. A postscript file is generated that can be converted to a desirable image format or portable document format.

\subsection{Validation of docking methodology.}

To validate our docking procedure, extracted predicted docking pose of S1-CTD from the S1-CTD-ACE2 complex was and subsequently superimposed to its native structure (PDB ID: 6LZG). The lowest deviation between docked and experimentally determined pose was identified [45-48].

\section{Results and Discussion}

\subsection{E-protein model evaluation and validation.}

Ramachandran plot of PROCHECK tool exhibited that $54.43 \%$ residues of the I-Tasser model and $84.4 \%$ residues of SMR model were located in its core region. However, a predicted model with $>90 \%$ residues in the core region is considered good [24]. QMEAN tool predicted 
a consensus-based distance constraint (DisCo) score called global score (GS) [25]. Global scores of both models were found $0.34 \pm 0.11$ and $0.36 \pm 0.05$, respectively. The possible error pertinent to the GS is based on the predicted and reference models' local Distance Difference Test (IDDT). The value of IDDT >0.6 is considered promising [49]. LG- and MaxSub-scores of I-Tasser model were found to be 4.098 and 0.257, respectively. However, the SMR model depicted LG- and MaxSub-scores of 0.879 and 0.029, respectively. 3D structure having LGand MaxSub-scores, respectively $>4$ and 0.8 is categorized as one of the best models $[27,28]$. In the aforesaid data purview, we analyzed that SMR model is supposedly better in comparison to the I-Tasser and therefore was selected for further docking studies.

\subsection{Rigid protein-protein docking.}

The rigid molecular docking of S1-CTD and E-protein with Fab fragment of IgG2a LA5 and IgA, as well as its host proteins ACE2 and MPP5, respectively, was carried out using Hex 8.0.0, ZDOCK, ClusPro and Patchdock tools [30-34]. It is known that the Hex predicts molecular interactions with the lowest free energy (Etotal) using an SPF algorithm allowing rigorous search space sampling to cluster solutions depicting similar binding orientation [30, 50]. Findings of Hex docking revealed that S1-CTD exhibited strong interaction with $\operatorname{IgG} 2 \mathrm{a}$ LA5 as depicted by its Etotal $(-758.0 \mathrm{~kJ} / \mathrm{mol})$, followed by $\operatorname{IgA}(-721.8 \mathrm{~kJ} / \mathrm{mol})$ and ACE2 ($354.3 \mathrm{~kJ} / \mathrm{mol})$. Docking stability of these interactants was calculated in terms of $\Delta \mathrm{G}\left(\mathrm{kcal} \mathrm{mol}^{-}\right.$ $\left.{ }^{1}\right)$ and $\mathrm{K}_{\mathrm{d}}(\mathrm{M})[41,42]$ that followed the order as- IgG2a LA5 ( $\left.\Delta \mathrm{G}:-17.5, \mathrm{~K}_{\mathrm{d}}: 1.4 \times 10^{-13}\right)>\operatorname{IgA}$ $\left(-17.1,3.1 \times 10^{-13}\right)>\operatorname{ACE} 2\left(-12.4,8.3 \times 10^{-10}\right)$. Likewise, E-protein showed a strong interaction with IgA (Etotal: $-696.6 \mathrm{~kJ} / \mathrm{mol})$ followed by IgG2a LA5 (-694.2 kJ/mol) and MPP5 (-545.9 $\mathrm{kJ} / \mathrm{mol}$ ). Further, a similar pattern was also observed in docking stability $\left(\Delta \mathrm{G}\right.$ and $\mathrm{K}_{\mathrm{d}}$ ) which was as follows- $\operatorname{IgA}\left(\Delta \mathrm{G}:-24.4, \mathrm{~K}_{\mathrm{d}}: 1.4 \times 10^{-18}\right)>\operatorname{IgG} 2 \mathrm{a} \operatorname{LA} 5\left(-16.2 ; 1.4 \times 10^{-12}\right)>\operatorname{MPP} 5(-9.4$, $\left.1.9 \times 10^{-7}\right)$ (Table 1 ).

Findings of ZDOCK Server highlighted that S1-CTD exhibited strong interaction with IgG2a LA5 as depicted by its Z-dock score (2268) followed by IgA (1525), and ACE2 (1457) $[37,51]$. Further, docking stability of these proteins was checked in terms of $\Delta \mathrm{G}\left(\mathrm{kcal} \mathrm{mol}^{-1}\right)$ and $\mathrm{K}_{\mathrm{d}}(\mathrm{M})$ [41, 42] that followed the order as- IgG2a LA5 ( $\left.\Delta \mathrm{G}:-21.1, \mathrm{~K}_{\mathrm{d}}: 1.0 \times 10^{-16}\right)>\operatorname{IgA}(-$ 20.2, 1.5 $\left.10^{-15}\right)>\operatorname{ACE} 2\left(-18.7,2.0 \times 10^{-14}\right)$. Moreover, E-protein showed a strong interaction with IgG2a LA5 (Zdock score: 1897) followed by IgA (1497), and MPP5 (1375). Further, a similar pattern was also detected in docking stability $\left(\Delta \mathrm{G}\right.$ and $\left.\mathrm{K}_{\mathrm{d}}\right)$ : IgG2a LA5 ( $\Delta \mathrm{G}:-20.7, \mathrm{~K}_{\mathrm{d}}$ : $\left.6.7 \times 10^{-16}\right)>\operatorname{IgA}\left(-18.1 ; 5.5 \times 10^{-14}\right)>\operatorname{MPP} 5\left(-15.7,3.2 \times 10^{-12}\right)$ (Table 1$)$.

ClusPro performed rigid docking in two stages; the first stage generates 1,000 low energy docked conformations using pairwise interaction potentials. The second stage includes retaining top 30 clusters showing minimum energy [32,33,38]. Findings of ClusPro docking revealed that S1-CTD exhibited strong interaction with $\operatorname{IgA}$ as depicted by its lowest energy function (-2268), followed by IgG2a LA5 (-844.5) and ACE2 (-790.7). Further, docking stability of these proteins was checked in terms of $\Delta \mathrm{G}\left(\mathrm{kcal} \mathrm{mol}^{-1}\right)$ and $\mathrm{K}_{\mathrm{d}}(\mathrm{M})$ [41, 42] that followed the order as- IgA $\left(\Delta \mathrm{G}:-19.2, \mathrm{~K}_{\mathrm{d}}: 7.8 \times 10^{-15}\right)>$ ACE2 $\left(-17.7,1.5 \times 10^{-10}\right)>\operatorname{IgG} 2 \mathrm{a}$ LA5 $\left(-17.2,2.5 \times 10^{-13}\right)$. Moreover, E-protein showed a strong interaction with $\operatorname{IgA}$ (Lowest energy: -1021.9) followed by IgG2a LA5 (-968.6) and MPP5 (-914.5). Similarly, a consistent pattern was also exhibited in docking stability $\left(\Delta \mathrm{G}\right.$ and $\left.\mathrm{K}_{\mathrm{d}}\right)$ which was as follows- IgG2a LA5 ( $\Delta \mathrm{G}$ : 19.3, $\left.\mathrm{K}_{\mathrm{d}}: 6.9 \times 10^{-15}\right)>\operatorname{IgA}\left(-18.5 ; 2.9 \times 10^{-15}\right)>\operatorname{MPP} 5\left(-11.2,6.6 \times 10^{-9}\right)$ (Table 1). 
Table 1. Docking analysis of S1-CTD and E-protein.

\begin{tabular}{|c|c|c|c|c|c|c|c|c|c|c|c|c|}
\hline \multirow[t]{2}{*}{ Proteins } & \multirow{2}{*}{$\begin{array}{c}\mathrm{A}^{\wedge} \\
\text { Etotal } \\
(\mathrm{kJ} / \mathrm{mol})\end{array}$} & \multirow{2}{*}{$\begin{array}{c}\mathbf{B}^{@} \\
\text { Dock } \\
\text { score }\end{array}$} & \multirow{2}{*}{$\begin{array}{c}\mathbf{C}^{\%} \\
\text { Energy } \\
\text { Score }\end{array}$} & \multirow{2}{*}{$\begin{array}{c}D^{\sim} \\
\text { Dock } \\
\text { score }\end{array}$} & \multicolumn{4}{|c|}{$\Delta \mathbf{G}\left(\right.$ kcal mol $^{-1) \$}$} & \multicolumn{4}{|c|}{$\mathbf{K}_{\mathbf{d}}(\mathbf{M})^{\$}$} \\
\hline & & & & & $A^{, \wedge}$ & $\mathbf{B}^{\prime @}$ & $C^{\prime} \%$ & $\mathbf{D}^{\prime} \sim$ & $A^{\prime \prime \wedge}$ & B',@ & C,\% & $\mathbf{D}^{\prime \prime} \sim$ \\
\hline S-ACE2* & -354.3 & 1457 & -790.7 & 14786 & -12.4 & -18.7 & -17.7 & -23.0 & $8.3 \times 10^{-10}$ & $2.0 \times 10^{-14}$ & $1.5 \times 10^{-10}$ & $1.4 \times 10^{-17}$ \\
\hline S-IgG & -758.0 & 2268 & -844.5 & 16318 & -17.5 & -21.1 & -17.2 & -28.2 & $1.4 \times 10^{-13}$ & $1.0 \times 10^{-16}$ & $2.5 \times 10^{-13}$ & $2.3 \times 10^{-22}$ \\
\hline S-IgA & -721.8 & 1525 & -2268 & 15520 & -17.1 & -20.2 & -19.2 & -25.2 & $3.1 \times 10^{-13}$ & $1.5 \times 10^{-15}$ & $7.8 \times 10^{-15}$ & $3.4 \times 10^{-19}$ \\
\hline E-MPP5 & -545.9 & 1375 & -914.5 & 11662 & -9.2 & -15.7 & -11.2 & -21.8 & $1.9 \times 10^{-7}$ & $3.2 \times 10^{-12}$ & $6.6 \times 10^{-9}$ & $5.6 \times 10^{-15}$ \\
\hline E-IgG & -694.2 & 1897 & -968.6 & 14612 & -16.2 & -20.7 & -19.3 & -26.3 & $1.4 \times 10^{-12}$ & $6.7 \times 10^{-16}$ & $6.9 \times 10^{-15}$ & $6.2 \times 10^{-20}$ \\
\hline E-IgA & -696.6 & 1497 & -1021.9 & 13982 & -24.4 & -18.1 & -18.5 & -22.7 & $1.4 \times 10^{-18}$ & $5.5 \times 10^{-14}$ & $2.9 \times 10^{-15}$ & $4.2 \times 10^{-16}$ \\
\hline
\end{tabular}

*S-Spike C-terminal domain (S1-CTD).

\#IgG-Fab fragment of IgG2a LA5.

$\$$ stability predicted by prodigy server.

'findings related to column A, A' and A'" predicted by Hex tool.

@ findings related to column B, B' and B'” predicted by ZDOCK tool.

"findings related to column C, C' and C'" predicted by ClusPro tool.

findings related to column D, D' and D', predicted by PatchDock tool.

Findings of PatchDock exhibited that S1-CTD exhibited strong interaction with IgG2a LA5 as depicted by its PatchDock score (16318) followed by IgA (15520), and ACE2 (14786) [39]. Further, consistent pattern was also found in docking stability in terms of $\Delta \mathrm{G} \mathrm{(kcal} \mathrm{mol}{ }^{-}$ $\left.{ }^{1}\right)$ and $\mathrm{K}_{\mathrm{d}}(\mathrm{M})[41,42]$ that followed the order as- IgG2a LA5 ( $\left.\Delta \mathrm{G}:-28.2, \mathrm{~K}_{\mathrm{d}}: 2.3 \times 10^{-22}\right)>\operatorname{IgA}$ $\left(-25.2,3.4 \times 10^{-19}\right)>$ ACE2 $\left(-23.0,1.4 \times 10^{-17}\right)$. Likewise, E-protein showed a strong interaction with IgG2a LA5 (PatchDock score: 14612) followed by IgA (13982), and MPP5 (11662). Similarly, stability pattern was also consistent that followed the order as - IgG2a LA5 ( $\Delta \mathrm{G}$ : $\left.26.3, \mathrm{~K}_{\mathrm{d}}: 6.2 \times 10^{-20}\right)>\operatorname{IgA}\left(-22.7 ; 4.2 \times 10^{-16}\right)>\operatorname{MPP} 5\left(-21.8,5.6 \times 10^{-15}\right)($ Table 1$)$.

It is evident from the above findings that both viral proteins (S1-CTD and E-protein) depicted strong and stable binding interactions with antibodies compared to their cognate host receptor proteins except ClusPro docking, wherein stability of S1-CTD with IgG2a LA5 was predicted lower to ACE2. Detailed rigid protein-protein docking analysis of all protein molecules and their stabilities are shown in Table 1.

\subsection{Flexible protein-protein docking.}

The flexible molecular docking of S1-CTD and E-protein with both antibodies and their host proteins ACE2 and MPP5 was carried out using HADDOCK tool that allows backbone and side-chains flexibility during docking execution of interacting molecules $[35,52,53]$.

\begin{tabular}{|c|c|c|c|c|c|c|c|c|c|c|c|}
\hline Proteins & $\begin{array}{l}\text { HADDOCK } \\
\text { score }\end{array}$ & $\begin{array}{l}\text { Cluster } \\
\text { size }\end{array}$ & $\begin{array}{l}\text { Docking } \\
\text { RMSD }\end{array}$ & $\begin{array}{l}\text { Z- } \\
\text { score }\end{array}$ & $\begin{array}{l}\text { VdW } \\
\text { energy }\end{array}$ & $\begin{array}{l}\text { Electrostatic } \\
\text { energy }\end{array}$ & $\begin{array}{l}\text { Desolvation } \\
\text { energy }\end{array}$ & $\begin{array}{l}\text { Restraints } \\
\text { violation } \\
\text { energy }\end{array}$ & $\begin{array}{l}\text { Buried surface } \\
\text { area }\end{array}$ & $\begin{array}{l}\Delta \mathbf{G}^{\$} \\
(\mathbf{k c a l} \\
\text { mol }^{-1)}\end{array}$ & $\mathbf{K}_{\mathbf{d}}(\mathbf{M})^{\$}$ \\
\hline S-ACE2* & $-89.6 \pm 17.3$ & 9 & $0.5 \pm 0.3$ & -1.8 & $-79.1 \pm 10.6$ & $-315.9 \pm 12.5$ & $-18.5 \pm 3.5$ & $2133.7 \pm 145.5$ & $2708.8 \pm 57.7$ & -15.5 & $4.3 \times 10^{-12}$ \\
\hline S-IgG & $-79.8 \pm 15.9$ & 11 & $18.6 \pm 0.2$ & -1.4 & $-52.3 \pm 4.4$ & $-579.2 \pm 54.9$ & $-27.2 \pm 2.8$ & $2208.1 \pm 116.4$ & $2262.5 \pm 42.8$ & -16.4 & $9.7 \times 10^{-12}$ \\
\hline S-IgA & $-125.5 \pm 19.2$ & 4 & $21.0 \pm 0.2$ & -1.2 & $-111.9 \pm 4.9$ & $-206.6 \pm 69.8$ & $-40.0 \pm 4.5$ & $3187.1 \pm 139.5$ & $3146.6 \pm 104.8$ & -19.4 & $6.4 \times 10^{-15}$ \\
\hline E-MPP5 & $-56.1 \pm 10.8$ & 7 & $1.5 \pm 0.9$ & -1.7 & $-73.6 \pm 2.6$ & $-177.0 \pm 44.4$ & $-40.3 \pm 5.2$ & $932.8 \pm 86.9$ & $2886.7 \pm 154.9$ & -12.9 & $3.4 \times 10^{-10}$ \\
\hline E-IgG & $-19.9 \pm 13.9$ & 8 & $10.2 \pm 0.1$ & -1.4 & $-87.1 \pm 8.5$ & $-94.8 \pm 9.7$ & $-43.2 \pm 4.2$ & $1294.0 \pm 150.4$ & $3372.7 \pm 57.5$ & -15.8 & $2.5 \times 10^{-12}$ \\
\hline E-IgA & $-6.6 \pm 20.0$ & 7 & $0.5 \pm 0.3$ & -1.6 & $-107.3 \pm 4.8$ & $-84.4 \pm 33.7$ & $-70.6 \pm 4.5$ & $2014.2 \pm 189.8$ & $3509.1 \pm 85.9$ & -16.0 & $1.9 \times 10^{-12}$ \\
\hline
\end{tabular}

HADDOCK score of S1-CTD with IgA (-125.5 \pm 19.2$)$ was more than ACE2 (-89.6 $\pm 17.3)$, and IgG2a LA5 (-79.8 \pm 15.9$)$, while E-protein exhibited stronger interaction with MPP5 (-56.1 \pm 10.8$)$ rather than IgG2a LA5 (-19.9 \pm 13.9$)$, and IgA (-6.6 \pm 20.0$)$. Z-scores of S1-CTD -ACE2 and E- MPP5 complexes were predicted more than antibodies. In terms of 
different energy functions (van der Waals-, electrostatic-, desolvation-, and restraint violation energy) docking RMSD, and buried surface area, no consistent docking pattern was observed between viral and cellular proteins (Table 2).

In addition to, docking affinity and stability of complexes having maximum HADDOCK scores were further calculated in terms of $\Delta \mathrm{G}\left(\mathrm{kcal} \mathrm{mol}^{-1}\right)$ and $\mathrm{K}_{\mathrm{d}}(\mathrm{M})$ wherein, S1-CTD showed the order as- IgA $\left(\Delta \mathrm{G}:-19.4, \mathrm{~K}_{\mathrm{d}}: 6.4 \times 10^{-15}\right)>\operatorname{IgG} 2 \mathrm{a}$ LA5 $\left(-16.4,9.7 \times 10^{-12}\right)$ $>$ ACE2 $\left(-15.5,4.3 \times 10^{-12}\right)$. Likewise, E-protein also showed strong binding affinity with IgA $\left(\Delta \mathrm{G}:-16.0, \mathrm{~K}_{\mathrm{d}}: 1.9 \times 10^{-12}\right)$ followed by $\operatorname{IgG} 2 \mathrm{a}$ LA5 $\left(-15.8 ; 2.5 \times 10^{-12}\right)>\operatorname{MPP} 5\left(-12.9,3.4 \times 10^{-}\right.$ ${ }^{10}$ ) [Table 2]. Detailed flexible protein-protein docking analysis of all protein molecules and their binding stabilities are shown in Table 2.

\subsection{Interface residues analysis.}

Findings obtained through Hex docking tool [30] exhibited that S1-CTDS1-CTD residues namely-ALA475, GLY476, ASN487, PHE456, TYR473, ASN489, LYS417, LEU455, GLU484, PHE486, PHE490, GLN493, TYR505, TYR449, GLY496, GLN498, THR500, ASN501, TYR453, LEU455, and TYR502 interact with GLN24, SER19, THR27, PHE28, TYR83, ASP30, LYS31, HIS34, LEU79, MET82, ARG393, GLY354, LYS353, GLU37, ASP38, GLN42, TYR41, LEU45, ASP355, ARG357, and ASN330 residues of ACE2, which is similar (except ALA36) to the interface binding pattern reported earlier by Wang $e t$ al., 2020 (Table S1) [15]. Two (GLY476 and PHE490) (Table S2) and six residues (ALA475, GLY476, ASN487, TYR473, PHE486, and ASN501) (Table S3) of S1-CTD were missing at the interface of IgG2a LA5, and IgA, respectively. Residues of S1-CTD making hydrophobic contacts and H-bondings with ACE2, IgG2a LA5, and IgA are shown in Figures 1-3.

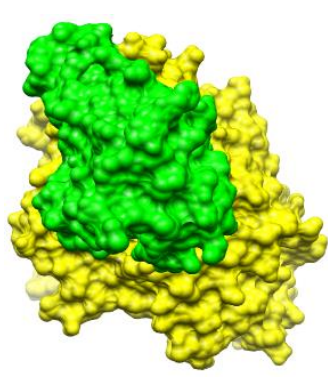

(a)

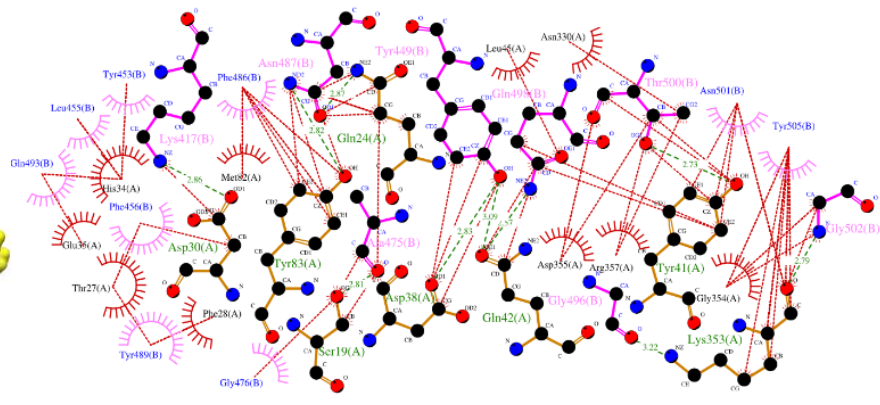

(b)

Figure 1. Docked complex of S1-CTD and ACE2 (a) Surface view-S1-CTD in green and ACE2 in yellow (b) DIMPLOT in which hydrophobic contacts and H-bonds are shown by dashed lines and arcs, respectively.

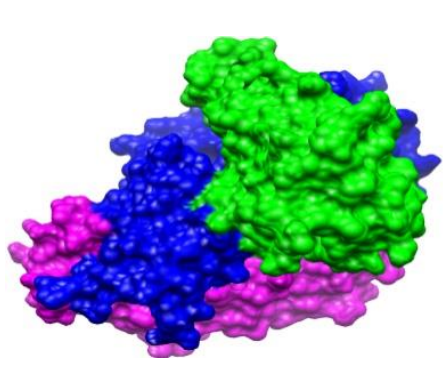

(a)

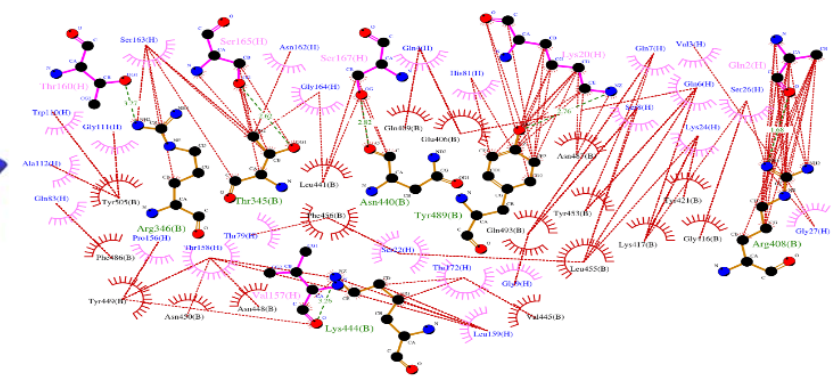

(b)

Figure 2. Docked complex of S1-CTD and IgG2a LA5 (a) Surface view-S1-CTD in green, H, and L chain of IgG2a LA5 respectively in blue and magenta (b) DIMPLOT in which hydrophobic contacts and H-bonds are shown by dashed lines and arcs, respectively. 


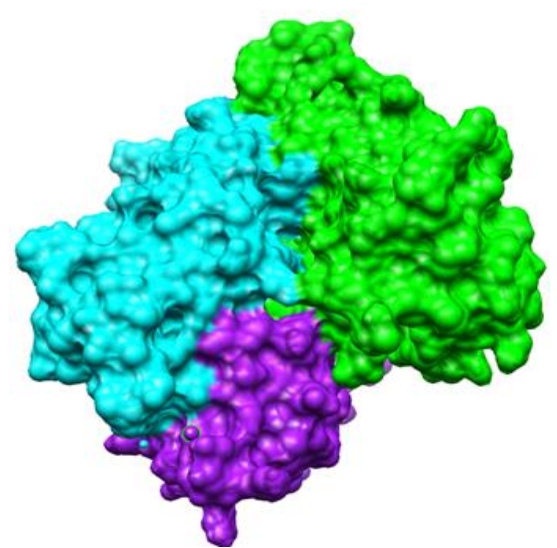

(a)

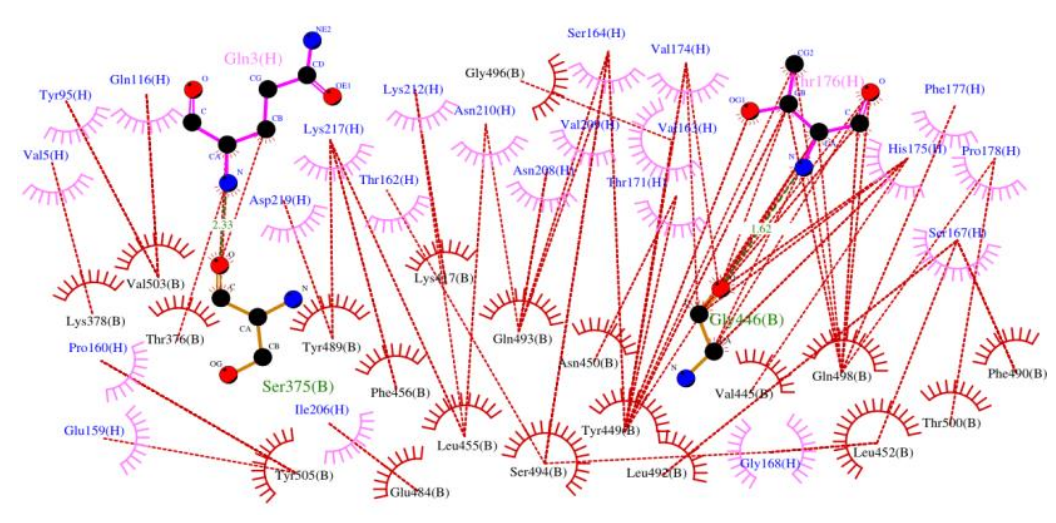

(b)

Figure 3. Docked complex of S1-CTD and IgA (a) Surface view-S1-CTD in green, H, and L chain of IgA respectively in cyan and purple (b) DIMPLOT in which hydrophobic contacts and H-bonds are shown by dashed lines and arcs, respectively.

Likewise, Hex docking results highlighted that E-protein residues namely-GLU8, GLY10, THR11, LEU12, ILE13, VAL14, ASN15, SER16, VAL17, LEU18, LEU19, LEU21, ALA22, PHE23, VAL25, PHE26, and VAL29 interact with ILE265, GLY268, LYS285, VAL284, LEU267, ALA288, PHE266, GLY287, LYS291, GLY286, ALA89, ASP264, PHE318, SER322, THR270, ALA269, VAL217, ARG272, VAL314, VAL317, GLU316, ASN315, ASP319, VAL271, ARG272, ARG28, THR270, SER281, ASN273, ASP313, MET275, and GLU274 residues of MPP5 (Table S4). All residues of E-protein are involved in molecular interaction with IgG2a LA5, and IgA (Table S5 and Table S6).

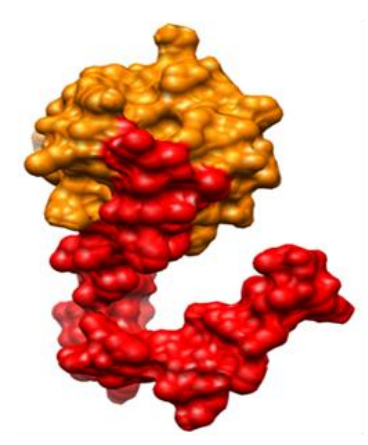

(a)

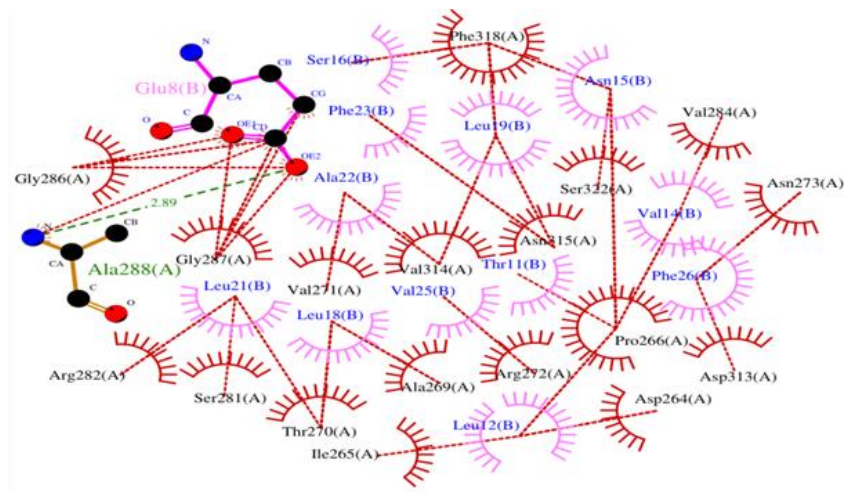

(b)

Figure 4. Docked complex of E-protein and MPP5 (a) Surface view-E-protein in red and MPP5 in orange (b) DIMPLOT in which hydrophobic contacts and H-bonds are shown by dashed lines and arcs, respectively.

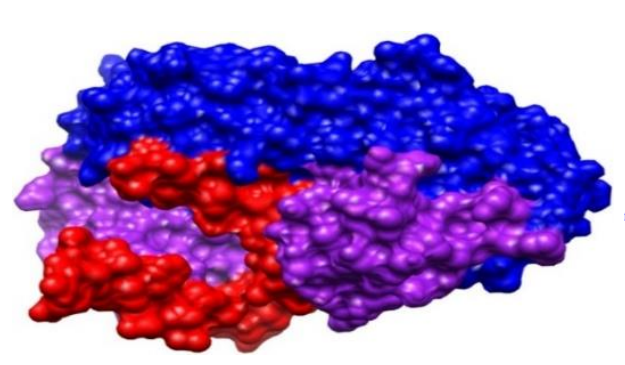

(a)

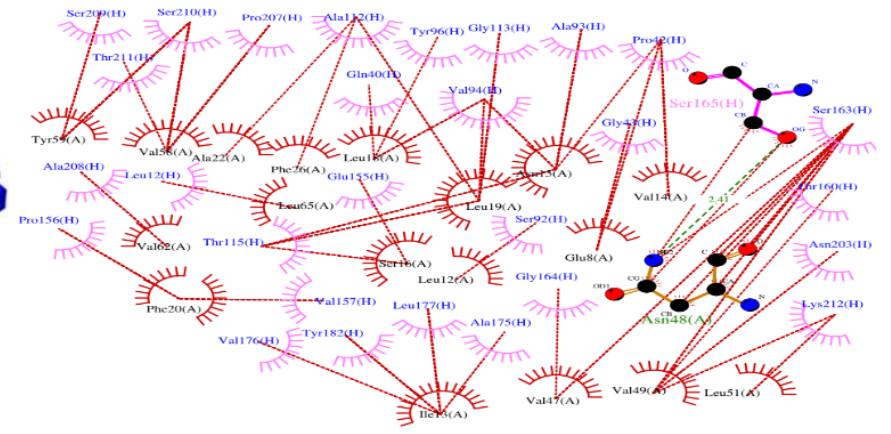

(b)

Figure 5. Docked complex of E-protein and IgG2a LA5 (a) Surface view-E-protein in red, H, and L chain of IgG2a LA5 respectively in blue and magenta (b) DIMPLOT in which hydrophobic contacts and H-bonds are shown by dashed lines and arcs, respectively. 
Only one residue VAL29 of E-protein is not involved in an interaction with IgG2a LA5. Residues of E-protein making hydrophobic contacts and H-bondings with MPP5, IgG2a LA5, and IgA are respectively shown in Figures 4-6.

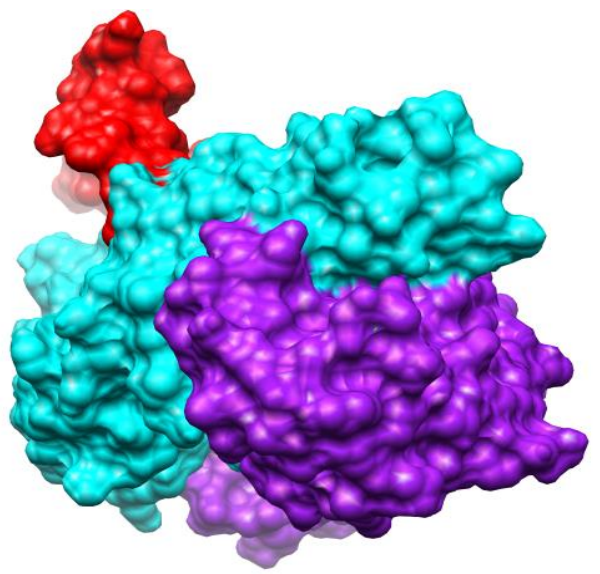

(a)

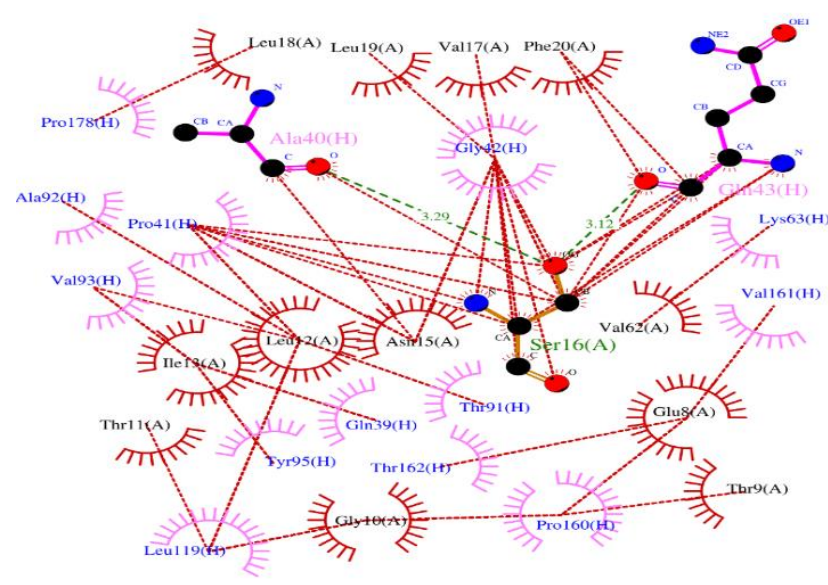

(b)

Figure 6. Docked complex of E-protein and $\operatorname{IgA}$ (a) Surface view-E-protein in red and $\mathrm{H}$ and $\mathrm{L}$ chain of $\operatorname{Ig} \mathrm{A}$ respectively in cyan and purple (b) DIMPLOT in which hydrophobic contacts and H-bonds are shown by dashed lines and arcs, respectively.

ZDOCK tool showed the involvement of almost all residues except three (ALA475, GLY476, and TYR473) in ACE2, and only one residue (GLY476) missing in IgG2a LA5. ClusPro docking exhibited the involvement of all residues in ACE2, missing all residues in IgG2a LA5, and six residues (ALA475, GLY476, ASN487, TYR473, LYS417, and PHE486) missing in IgA. PatchDock tool showed three residues (ASN487, PHE486, and PHE490) missing in ACE2, five residues (ALA475, GLY476, ASN487, TYR473, and PHE486) missing in IgG2a LA5, and missing of all residues in IgA except one (TYR505). HADDOCK tool exhibited missing of all residues except one (THR500) in ACE2, nine residues (ASN489, GLU484, PHE486, PHE490, GLN493, TYR449, GLY496, GLN498, and THR500) missing in IgG2a LA5, and four residues (ALA475, GLY476, TYR473, and LYS417) missing in IgA. It is evident from residue analysis that most of the tools predicted true positive results, which favors the engagement of S1-CTD and E-proteins key residues with other proteins. Overall interacting and missed residues of S1-CTD and E-protein with their cognate receptors and Abs are summarized in Table 3 and Table 4.

Table 3. S1-CTD interface residues analysis.

\begin{tabular}{|c|c|c|c|c|c|c|c|c|c|c|c|c|c|c|c|c|}
\hline \multirow{2}{*}{$\begin{array}{l}\text { S. } \\
\text { No. }\end{array}$} & \multirow[t]{2}{*}{ Residues $^{\$}$} & \multicolumn{3}{|l|}{ Hex } & \multicolumn{3}{|c|}{ ZDOCK } & \multicolumn{3}{|c|}{ ClusPro } & \multicolumn{3}{|c|}{ PatchDock } & \multicolumn{3}{|c|}{ HADDOCK $^{\&}$} \\
\hline & & ACE2 & IgG $^{\#}$ & IgA & ACE2 & IgG & IgA & ACE2 & IgG & IgA & ACE2 & IgG & IgA & ACE2 & IgG & IgA \\
\hline 1. & ALA475 & $\checkmark$ & $\checkmark$ & $x$ & $x$ & $\sqrt{2}$ & $\checkmark$ & $\checkmark$ & $x$ & $x$ & $\checkmark$ & $x$ & $x$ & $x$ & $\checkmark$ & $\times$ \\
\hline 2. & GLY476 & $\checkmark$ & $x$ & $x$ & $x$ & $x$ & $\checkmark$ & $\checkmark$ & $x$ & $x$ & $\checkmark$ & $x$ & $x$ & $x$ & $\checkmark$ & $x$ \\
\hline 3. & ASN487 & $\checkmark$ & $\checkmark$ & $x$ & $\checkmark$ & $\checkmark$ & $\checkmark$ & $\checkmark$ & $x$ & $x$ & $x$ & $x$ & $x$ & $x$ & $\checkmark$ & $\checkmark$ \\
\hline 4. & PHE456 & $\checkmark$ & $\checkmark$ & $\checkmark$ & $\checkmark$ & $\checkmark$ & $\checkmark$ & $\checkmark$ & $x$ & $\checkmark$ & $\checkmark$ & $\checkmark$ & $x$ & $x$ & $\checkmark$ & $\checkmark$ \\
\hline 5. & TYR473 & $\checkmark$ & $\checkmark$ & $x$ & $x$ & $x$ & $\checkmark$ & $\checkmark$ & $x$ & $x$ & $\checkmark$ & $x$ & $x$ & $\times$ & $\checkmark$ & $x$ \\
\hline 6. & ASN489 & $\checkmark$ & $\checkmark$ & $\checkmark$ & $\checkmark$ & $\checkmark$ & $\checkmark$ & $\checkmark$ & $x$ & $\checkmark$ & $\checkmark$ & $\checkmark$ & $x$ & $x$ & $x$ & $\checkmark$ \\
\hline 7. & LYS417 & $\checkmark$ & $\checkmark$ & $\checkmark$ & $\checkmark$ & $\checkmark$ & $\checkmark$ & $\checkmark$ & $x$ & $x$ & $\checkmark$ & $\checkmark$ & $x$ & $x$ & $\checkmark$ & $x$ \\
\hline 8. & LEU455 & $\checkmark$ & $\checkmark$ & $\checkmark$ & $\checkmark$ & $\checkmark$ & $\checkmark$ & $\checkmark$ & $x$ & $\checkmark$ & $\checkmark$ & $\checkmark$ & $x$ & $x$ & $\checkmark$ & $\checkmark$ \\
\hline 9. & GLU484 & $\checkmark$ & $\checkmark$ & $\checkmark$ & $\checkmark$ & $\checkmark$ & $\checkmark$ & $\checkmark$ & $x$ & $\checkmark$ & $\checkmark$ & $\checkmark$ & $x$ & $x$ & $x$ & $\checkmark$ \\
\hline 10. & PHE486 & $\checkmark$ & $\checkmark$ & $x$ & $\checkmark$ & $\checkmark$ & $\checkmark$ & $\checkmark$ & $x$ & $x$ & $x$ & $x$ & $x$ & $x$ & $x$ & $\checkmark$ \\
\hline 11. & PHE490 & $\checkmark$ & $x$ & $\checkmark$ & $\checkmark$ & $\checkmark$ & $\checkmark$ & $\checkmark$ & $x$ & $\checkmark$ & $x$ & $\checkmark$ & $x$ & $x$ & $x$ & $\checkmark$ \\
\hline 12. & GLN493 & $\checkmark$ & $\checkmark$ & $\checkmark$ & $\checkmark$ & $\checkmark$ & $\checkmark$ & $\checkmark$ & $x$ & $\checkmark$ & $\checkmark$ & $\checkmark$ & $x$ & $x$ & $x$ & $\checkmark$ \\
\hline 13. & TYR505 & $\checkmark$ & $\checkmark$ & $\checkmark$ & $\checkmark$ & $\checkmark$ & $\checkmark$ & $\checkmark$ & $x$ & $\checkmark$ & $\checkmark$ & $\checkmark$ & $\checkmark$ & $x$ & $\checkmark$ & $\checkmark$ \\
\hline 14. & TYR449 & $\checkmark$ & $\checkmark$ & $\checkmark$ & $\checkmark$ & $\checkmark$ & $\checkmark$ & $\checkmark$ & $x$ & $\checkmark$ & $\checkmark$ & $\checkmark$ & $x$ & $x$ & $x$ & $\checkmark$ \\
\hline 15. & GLY496 & $\checkmark$ & $\checkmark$ & $\checkmark$ & $\checkmark$ & $\checkmark$ & $\checkmark$ & $\checkmark$ & $x$ & $\checkmark$ & $\checkmark$ & $\checkmark$ & $x$ & $x$ & $x$ & $\checkmark$ \\
\hline 16. & GLN498 & $\checkmark$ & $\checkmark$ & $\checkmark$ & $\checkmark$ & $\checkmark$ & $\checkmark$ & $\checkmark$ & $x$ & $\checkmark$ & $\checkmark$ & $\checkmark$ & $x$ & $x$ & $x$ & $\bar{\checkmark}$ \\
\hline
\end{tabular}




\begin{tabular}{|c|c|c|c|c|c|c|c|c|c|c|c|c|c|c|c|c|}
\hline \multirow{2}{*}{$\begin{array}{l}\text { S. } \\
\text { No. }\end{array}$} & \multirow[t]{2}{*}{ Residues\$ } & \multicolumn{3}{|l|}{ Hex } & \multicolumn{3}{|c|}{ ZDOCK } & \multicolumn{3}{|c|}{ ClusPro } & \multicolumn{3}{|c|}{ PatchDock } & \multicolumn{3}{|c|}{ HADDOCK $^{\&}$} \\
\hline & & ACE2 & IgG $^{\#}$ & IgA & ACE2 & IgG & $\operatorname{Ig} \mathbf{A}$ & ACE2 & IgG & IgA & ACE2 & IgG & IgA & ACE2 & IgG & IgA \\
\hline 17. & THR500 & $\checkmark$ & $\checkmark$ & $\checkmark$ & $\checkmark$ & $\checkmark$ & $\checkmark$ & $\checkmark$ & $\times$ & $\checkmark$ & $\checkmark$ & $\checkmark$ & $\times$ & $\checkmark$ & $\times$ & $\checkmark$ \\
\hline 18. & ASN501 & $\checkmark$ & $\checkmark$ & $x$ & $\checkmark$ & $\checkmark$ & $\checkmark$ & $\checkmark$ & $x$ & $\checkmark$ & $\checkmark$ & $\checkmark$ & $x$ & $x$ & $\checkmark$ & $\checkmark$ \\
\hline 19. & TYR453 & $\checkmark$ & $\checkmark$ & $\checkmark$ & $\checkmark$ & $\checkmark$ & $\checkmark$ & $\checkmark$ & $x$ & $\checkmark$ & $\checkmark$ & $\checkmark$ & $x$ & $x$ & $\checkmark$ & $\checkmark$ \\
\hline 20. & LEU455 & $\checkmark$ & $\checkmark$ & $\checkmark$ & $\checkmark$ & $\checkmark$ & $\checkmark$ & $\checkmark$ & $x$ & $\checkmark$ & $\checkmark$ & $\checkmark$ & $x$ & $x$ & $\checkmark$ & $\checkmark$ \\
\hline 21. & TYR502 & $\checkmark$ & $\checkmark$ & $\checkmark$ & $\checkmark$ & $\checkmark$ & $\checkmark$ & $\checkmark$ & $x$ & $\checkmark$ & $\checkmark$ & $\checkmark$ & $x$ & $x$ & $\checkmark$ & $\checkmark$ \\
\hline
\end{tabular}

Table 4. E-protein interface residues analysis.

\begin{tabular}{|c|c|c|c|c|c|c|c|c|c|c|c|c|c|c|c|}
\hline \multirow{2}{*}{$\begin{array}{c}\text { S. } \\
\text { No. }\end{array}$} & \multirow[t]{2}{*}{ Residues\$ } & \multicolumn{2}{|c|}{ Hex } & \multicolumn{3}{|c|}{ ZDOCK } & \multicolumn{3}{|c|}{ ClusPro } & \multicolumn{3}{|c|}{ PatchDock } & \multicolumn{3}{|c|}{ HADDOCK $^{\&}$} \\
\hline & & IgG $^{\#}$ & IgA & MPP5 & IgG & IgA & MPP5 & IgG & IgA & MPP5 & IgG & IgA & MPP5 & IgG & IgA \\
\hline 1. & GLU8 & $\checkmark$ & $\checkmark$ & $x$ & $x$ & $\checkmark$ & $x$ & $\checkmark$ & $\checkmark$ & $\times$ & $\times$ & $x$ & $x$ & $\checkmark$ & $x$ \\
\hline 2. & GLY10 & $\checkmark$ & $\checkmark$ & $x$ & $\checkmark$ & $\checkmark$ & $x$ & $\checkmark$ & $\checkmark$ & $x$ & $\checkmark$ & $\checkmark$ & $x$ & $x$ & $x$ \\
\hline 3. & THR11 & $\checkmark$ & $\checkmark$ & $\checkmark$ & $\checkmark$ & $\checkmark$ & $x$ & $\checkmark$ & $\checkmark$ & $x$ & $\checkmark$ & $x$ & $x$ & $x$ & $\checkmark$ \\
\hline 4. & LEU12 & $\checkmark$ & $\checkmark$ & $x$ & $\checkmark$ & $\checkmark$ & $x$ & $\checkmark$ & $\checkmark$ & $x$ & $\checkmark$ & $\checkmark$ & $x$ & $x$ & $\checkmark$ \\
\hline 5. & ILE13 & $\checkmark$ & $\checkmark$ & $\checkmark$ & $\checkmark$ & $\checkmark$ & $\checkmark$ & $\checkmark$ & $\checkmark$ & $x$ & $\checkmark$ & $x$ & $\checkmark$ & $x$ & $\checkmark$ \\
\hline 6. & VAL14 & $\checkmark$ & $\checkmark$ & $\checkmark$ & $\checkmark$ & $\checkmark$ & $x$ & $\checkmark$ & $\checkmark$ & $x$ & $x$ & $x$ & $x$ & $\checkmark$ & $\checkmark$ \\
\hline 7. & ASN15 & $\checkmark$ & $\checkmark$ & $\checkmark$ & $\checkmark$ & $\checkmark$ & $x$ & $x$ & $\checkmark$ & $\checkmark$ & $\checkmark$ & $x$ & $x$ & $x$ & $\checkmark$ \\
\hline 8. & SER16 & $\checkmark$ & $\checkmark$ & $\checkmark$ & $\checkmark$ & $\checkmark$ & $\checkmark$ & $x$ & $\checkmark$ & $\checkmark$ & $\checkmark$ & $x$ & $\checkmark$ & $x$ & $\checkmark$ \\
\hline 9. & VAL17 & $\checkmark$ & $\checkmark$ & $\checkmark$ & $\checkmark$ & $\checkmark$ & $\checkmark$ & $\checkmark$ & $\checkmark$ & $x$ & $x$ & $x$ & $\checkmark$ & $\checkmark$ & $\checkmark$ \\
\hline 10. & LEU18 & $\checkmark$ & $\checkmark$ & $\checkmark$ & $\checkmark$ & $x$ & $x$ & $\checkmark$ & $\checkmark$ & $x$ & $x$ & $x$ & $x$ & $\checkmark$ & $\checkmark$ \\
\hline 11. & LEU19 & $\checkmark$ & $\checkmark$ & $\checkmark$ & $\checkmark$ & $x$ & $x$ & $\checkmark$ & $\checkmark$ & $\checkmark$ & $\checkmark$ & $x$ & $\checkmark$ & $x$ & $\checkmark$ \\
\hline 12. & LEU21 & $\checkmark$ & $\checkmark$ & $\checkmark$ & $\checkmark$ & $\checkmark$ & $\checkmark$ & $\checkmark$ & $\checkmark$ & $x$ & $x$ & $x$ & $x$ & $\checkmark$ & $\checkmark$ \\
\hline 13. & ALA22 & $\checkmark$ & $\checkmark$ & $\checkmark$ & $\checkmark$ & $x$ & $x$ & $\checkmark$ & $\checkmark$ & $\checkmark$ & $x$ & $x$ & $\checkmark$ & $\checkmark$ & \\
\hline 14. & PHE23 & $\checkmark$ & $\checkmark$ & $\checkmark$ & $\checkmark$ & $\checkmark$ & $\checkmark$ & $\checkmark$ & $\checkmark$ & $\checkmark$ & $\checkmark$ & $x$ & $\checkmark$ & $\checkmark$ & $\checkmark$ \\
\hline 15. & VAL25 & $\checkmark$ & $\checkmark$ & $\checkmark$ & $\checkmark$ & $\checkmark$ & $x$ & $\checkmark$ & $x$ & $x$ & $x$ & $x$ & $\checkmark$ & $\checkmark$ & $x$ \\
\hline 16. & PHE26 & $\checkmark$ & $\checkmark$ & $x$ & $x$ & $\checkmark$ & $x$ & $\checkmark$ & $\checkmark$ & $\checkmark$ & $\checkmark$ & $\checkmark$ & $\checkmark$ & $\checkmark$ & $x$ \\
\hline 17. & VAL29 & $x$ & $\checkmark$ & $x$ & $x$ & $x$ & $x$ & $\checkmark$ & $\checkmark$ & $\checkmark$ & $\checkmark$ & $\checkmark$ & $\checkmark$ & $x$ & $x$ \\
\hline
\end{tabular}

\$Predicted Interface residues between E and MPP5 using the Hex tool due to the unavailability of its complex structure in PDB. The rationale behind its priority over other docking tools used due to its better performance in protein-protein docking benchmarking [50].

\#IgG- Fab fragment of IgG2a LA5.

${ }^{\&}$ Flexible docking tools, while others are rigid docking tools.

The year 2020 and the last quarter of the year 2019 have witnessed >22,000 articles and $>2000$ ongoing trials on COVID-19. Moreover, high-throughput sequencing and interdisciplinary approaches have provided advanced and quick information about 53 humans and viral proteins, accelerating the scientific fraternity to uncover the curtain from the tangled tale of the COVID-19 outbreak [2,3]. Scientists are using every preventive and therapeutic strategy, whether it is testing of clot-busting drugs, monoclonal antibodies, or convalescent plasma, to develop substantial drugs and vaccine candidates. Moreover, a comparison among different countries having mandated and not mandated BCG policies and its effectiveness against the COVID-19 outbreak was made by Berg et al., 2020. The findings of their study reveal that cases of COVID-19 and its related deaths were observed less in the BCG mandated countries in comparison to the non-mandated BCG countries [58].

Our study explored the hotspot residues of SARS-CoV-2 S1-CTD interacted with ACE2 reported previously [15], whether they are involved at the interface with other receptor proteins or not. These findings consistently highlighted the S1-CTD, and E-protein hotspot residues as key players in molecular interaction with IgG2a LA5, and IgA. The majority of the protein-protein interaction tools are based on the simple scoring functions like shape complementarity of interacting partners, excluding key structural properties like $\mathrm{pH}$, temperature, and $\mathrm{K}_{\mathrm{d}}[54,55]$. Therefore, we also checked the binding strength of viral proteins with the inclusion of structural features in terms of $\Delta \mathrm{G}$ and $\mathrm{K}_{\mathrm{d}}$ [42]. Abs's binding affinity with 
aforesaid viral proteins, is reflected greater than their cognate host protein responsible for cellular entry and subsequent modification and survival (Tables 1-2). This interface attributes playing key roles in the host entry might be promising therapeutic sites and immunogen for novel vaccine candidate design as in SARS-CoV and MERS-CoV, where their receptor binding proteins induced to generate an ample amount of neutralizing Abs [56, 57]. The study's findings obtained through different docking tools are almost consistent with respect to the binding affinity and engagement of hotspots residues that might confer the establishment of nonspecific immunity. Moreover, the study also provides structural insight into the existing vaccines at the molecular level. It supports Berg et al., 2020 findings [58].

\subsection{Validation of docking simulation.}

To validate our docking procedure, extracted S1-CTD from its crystal structure and redocked using Hex, ZDOCK, ClusPro, and PatchDock tools. Superimposition of the best pose obtained from each docking tools into its PDB pose exhibited minimum deviation. The molecular binding orientation of all the poses into the same binding cavity of ACE2 validates our docking procedures (Figure 7).

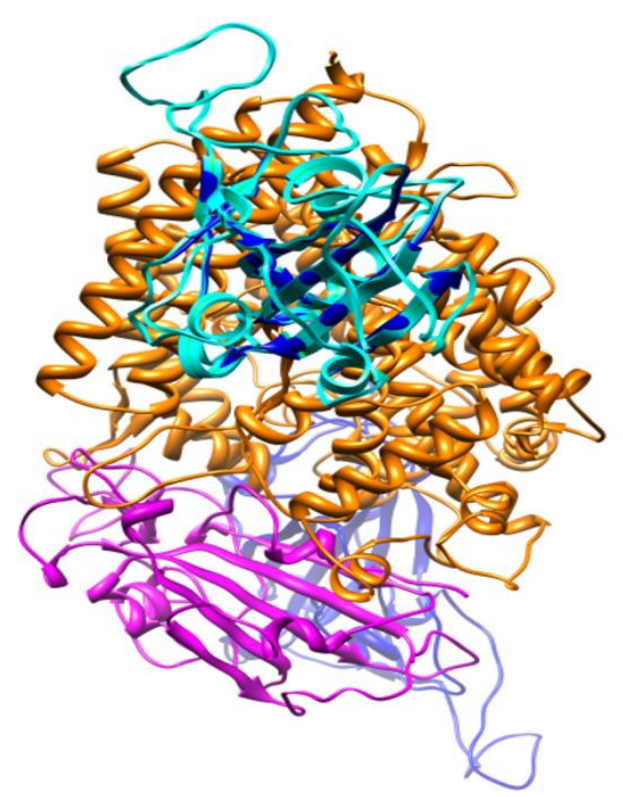

Figure 7. Validation of docking methodology by showing the same binding orientation of the native S1-CTD (green) co-complexed with ACE2 (orange) and that after re-docking the same (Hex-yellow, ZDOCK-cyan,

Cluspro-blue, and PatchDock-magenta).

\section{Conclusions}

According to the statistics, till October 10, 2020 (12:46 GMT), 37,175,477 cases of COVID-19 were reported, in which 1,073,673 people lost their lives globally (https://www.worldometers.info/coronavirus/). So, the earliest possible prevention and therapeutic measures are the prime demand of the current predicament. Towards this direction, an attempt was made to show the structural insight into the binding pattern of S1-CTD, and Eprotein with their host receptors ACE2 and MPP5, respectively, along with their neutralizing antibodies IgG2a LA5 and IgA. Findings depicted that Abs interacted more efficiently compared to ACE2 and MPP5 and formed a relatively stable structure with greater $\Delta \mathrm{G}$, indicating the use of existing vaccines as a preventive measure against COVID-19. Further, 
detailed hotspot residue analysis and its key role in molecular interaction will help design and develop non-specific vaccine candidates and immunotherapeutics against SARS-CoV-2.

\section{Funding}

This research received no external funding.

\section{Acknowledgments}

This work was supported by Integral University, Lucknow, India.

\section{Conflicts of Interest}

The authors declare no conflict of interest.

\section{References}

1. Li, H.; Liu, S.M.; Yu, X.H.; Tang, S.L.; Tang, C.K. Coronavirus disease 2019 (COVID-19): current status and future perspectives. Int. J. Antimicrob. Agents 2020, 55, https://doi.org/10.1016/j.ijantimicag.2020.105951.

2. https://www.sciencemag.org/news/2020/06/we-ve-got-be-able-move-more-quickly-pandemic-realitycovid-19-clinical-trials.

3. https://covid-19.uniprot.org/ accessed on October 08, 2020.

4. Thanh Le, T.; Andreadakis, Z.; Kumar, A.; Gómez Román, R.; Tollefsen, S.; Saville, M.; Mayhew, S. The COVID-19 Vaccine Development Landscape. Nat. Rev. Drug. Discov. 2020, 19, 305-306, https://doi.org/10.1038/d41573-020-00073-5.

5. Lurie, N.; Saville, M.; Hatchett, R.; Halton, J. Developing Covid-19 Vaccines at Pandemic Speed. N. Engl. J. Med. 2020, 382, 1969-1973, https://doi.org/10.1056/NEJMp2005630.

6. World Health Organization. DRAFT landscape of COVID-19 candidate vaccines-20 March 2020.

7. Vrieze, J. Can a Century-Old TB Vaccine Steel the Immune System against the New Coronavirus? Science 2020, https://doi.org/10.1126/science.abb8297.

8. O’Neill, L.A.J.; Netea, M.G. BCG-Induced Trained Immunity: Can It Offer Protection against COVID-19? Nat. Rev. Immunol. 2020, 20, 335-337, https://doi.org/10.1038/s41577-020-0337-y.

9. de Bree, C.L.C.J.; Marijnissen, R.J.; Kel, J.M.; Huber, S.K.R.; Aaby, P.; Benn, C S.; Wijnands, M.V.W.; Diavatopoulos, D.A.; Crevel, R. van; Joosten, L.A.B.; Netea, M.G.; Dulos, J. Bacillus Calmette-GuérinInduced Trained Immunity Is Not Protective for Experimental Influenza A/Anhui/1/2013 (H7N9) Infection in Mice. Front. Immunol. 2018, 9, https://doi.org/10.3389/fimmu.2018.00869.

10. Bacille, C.G. Vaccination and COVID-19. Scientific Brief. Pediatr. Med. Rodz. 2020, 16, 124-124, https://doi.org/10.15557/PiMR.2020.0025.

11. Aaby, P.; Benn, C.S. Developing the Concept of Beneficial Non-Specific Effect of Live Vaccines with Epidemiological Studies. Clinical Microbiology and Infection 2019, 25, 1459-1467, https://doi.org/10.1016/j.cmi.2019.08.011.

12. Moorlag, S.J.C.F.M.; Arts, R.J.W.; van Crevel, R.; Netea, M.G. Non-Specific Effects of BCG Vaccine on Viral Infections. Clin. Microbiol. Infect. 2019, 25, 1473-1478, https://doi.org/10.1016/j.cmi.2019.04.020.

13. Arts, R.J.W.; Moorlag, S.J.C.F.M.; Novakovic, B.; Li, Y.; Wang, S.Y.; Oosting, M.; Kumar, V.; Xavier, R.J.; Wijmenga, C.; Joosten, L.A.B.; Reusken, C.B E.M.; Benn, C.S.; Aaby, P.; Koopmans, M.P.; Stunnenberg, H.G.; van Crevel, R.; Netea, M.G. BCG Vaccination Protects against Experimental Viral Infection in Humans through the Induction of Cytokines Associated with Trained Immunity. Cell. Host. Microbe. 2018. 23, 89-100, https://doi.org/10.1016/j.chom.2017.12.010.

14. Uthayakumar, D.; Paris, S.; Chapat, L.; Freyburger, L.; Poulet, H.; De Luca, K. Non-Specific Effects of Vaccines Illustrated Through the BCG Example: From Observations to Demonstrations. Front. Immunol. 2018, 9, https://doi.org/10.3389/fimmu.2018.02869.

15. Wang, Q.; Zhang, Y.; Wu, L.; Niu, S.; Song, C.; Zhang, Z.; Lu, G.; Qiao, C.; Hu, Y.; Yuen, K.Y.; Wang, Q.; Zhou, H.; Yan, J.; Qi, J. Structural and Functional Basis of SARS-CoV-2 Entry by Using Human ACE2. Cell. 2020, 181, 894-904, https://doi.org/10.1016/j.cell.2020.03.045.

16. Prompetchara, E.; Ketloy, C.; Palaga, T. Immune Responses in COVID-19 and Potential Vaccines: Lessons Learned from SARS and MERS Epidemic. Asian. Pac. J. Allergy. Immunol. 2020, 38, 1-9, https://doi.org/10.12932/AP-200220-0772.

17. Wang, C.; Horby, P.W.; Hayden, F.G.; Gao, G.F. A Novel Coronavirus Outbreak of Global Health Concern. The Lancet 2020, 395, 470-473, https://doi.org/10.1016/S0140-6736(20)30185-9. 
18. Zhou, P.; Yang, X.Lou; Wang, X.G.; Hu, B.; Zhang, L.; Zhang, W.; Si, H.R.; Zhu, Y.; Li, B.; Huang, C.L.; Chen, H.D.; Chen, J.; Luo, Y.; Guo, H.; Jiang, R.Di; Liu, M.Q.; Chen, Y.; Shen, X.R.; Wang, X.; Zheng, X.S.; Zhao, K.; Chen, Q.J.; Deng, F.; Liu, L.L.; Yan, B.; Zhan, F.X.; Wang, Y.Y.; Xiao, G.F.; Shi, Z.L. A Pneumonia Outbreak Associated with a New Coronavirus of Probable Bat Origin. Nature 2020, 579, 270273, https://doi.org/10.1038/s41586-020-2012-7.

19. Astuti, I.; Ysrafil. Severe Acute Respiratory Syndrome Coronavirus 2 (SARS-CoV-2): An overview of viral structure and host response. Diabetes. Metab. Syndr. 2020, 14, 407-412, https://doi.org/10.1016/j.dsx.2020.04.020.

20. Hoffmann, M.; Kleine-Weber, H.; Schroeder, S.; Krüger, N.; Herrler, T.; Erichsen, S.; Schiergens, T.S.; Herrler, G.; Wu, N.H.; Nitsche, A.; Müller, M.A.; Drosten, C.; Pöhlmann, S. SARS-CoV-2 Cell Entry Depends on ACE2 and TMPRSS2 and Is Blocked by a Clinically Proven Protease Inhibitor. Cell 2020, 181, 271-280, https://doi.org/10.1016/j.cell.2020.02.052.

21. Matho, M.H.; Maybeno, M.; Benhnia, M.R.-E.-I.; Becker, D.; Meng, X.; Xiang, Y.; Crotty, S.; Peters, B.; Zajonc, D.M. Structural and Biochemical Characterization of the Vaccinia Virus Envelope Protein D8 and Its Recognition by the Antibody LA5. J. Virol. 2012, 86, 8050-8058, https://doi.org/10.1128/jvi.00836-12.

22. Shanker, S.; Czakó, R.; Sapparapu, G.; Alvarado, G.; Viskovska, M.; Sankaran, B.; Atmar, R.L.; Crowe, J.E.; Estes, M.K.; Venkataram Prasad, B.V. Structural Basis for Norovirus Neutralization by an HBGA Blocking Human IgA Antibody. Proc. Natl. Acad. Sci. U. S. A. 2016, 113, E5830-E5837, https://doi.org/10.1073/pnas.1609990113.

23. Ivanova, M.E.; Fletcher, G.C.; O’Reilly, N.; Purkiss, A.G.; Thompson, B.J.; McDonald, N.Q.Structures of the Human Pals1 PDZ Domain with and without Ligand Suggest Gated Access of Crb to the PDZ PeptideBinding Groove. Acta. Crystallogr. D. Biol. Crystallogr. 2015, 71, 555-564, https://doi.org/10.1107/S139900471402776X.

24. Laskowski, R.A.; MacArthur, M.W.; Moss, D.S.; Thornton, J.M. PROCHECK: A Program to Check the Stereochemical Quality of Protein Structures. J. Appl. Crystallogr. 1993, 26, 283-291, https://doi.org/10.1107/s0021889892009944.

25. Studer, G.; Rempfer, C.; Waterhouse, A. M.; Gumienny, R.; Haas, J.; Schwede, T. QMEANDisCo-Distance Constraints Applied on Model Quality Estimation. Bioinformatics 2020, 36, 1765-1771, https://doi.org/10.1093/bioinformatics/btz828.

26. Cristobal, S.; Zemla, A.; Fischer, D.; Rychlewski, L.; Elofsson, A. A Study of Quality Measures for Protein Threading Models. BMC Bioinformatics 2001, 2, https://doi.org/10.1186/1471-2105-2-5.

27. Levitt, M.; Gerstein, M. A Unified Statistical Framework for Sequence Comparison and Structure Comparison. Proc. Natl. Acad. Sci. U. S. A. 1998, 95, 5913-5920, https://doi.org/10.1073/pnas.95.11.5913.

28. Siew, N.; Elofsson, A.; Rychlewski, L.; Fischer, D. MaxSub: An Automated Measure for the Assessment of Protein Structure Prediction Quality. Bioinformatics 2000, 16, 776-785, https://doi.org/10.1093/bioinformatics/16.9.776.

29. Brooks, B.R.; Bruccoleri, R.E.; Olafson, B.D.; States, D.J.; Swaminathan, S.; Karplus, M. CHARMM: A Program for Macromolecular Energy, Minimization, and Dynamics Calculations. J. Comput. Chem. 1983, 4, 187-217, https://doi.org/10.1002/jcc.540040211.

30. Macindoe, G.; Mavridis, L.; Venkatraman, V.; Devignes, M.D.; Ritchie, D.W. HexServer: An FFT-Based Protein Docking Server Powered by Graphics Processors. Nucleic Acids. Res. 2010, 38, W445-449, https://doi.org/10.1093/nar/gkq311.

31. Pierce, B.G.; Wiehe, K.; Hwang, H.; Kim, B.H.; Vreven, T.; Weng, Z. ZDOCK Server: Interactive Docking Prediction of Protein-Protein Complexes and Symmetric Multimers. Bioinformatics 2014, 30, 1771-1773, https://doi.org/10.1093/bioinformatics/btu097.

32. Vajda, S.; Yueh, C.; Beglov, D.; Bohnuud, T.; Mottarella, S.E.; Xia, B.; Hall, D.R.; Kozakov, D. New additions to the ClusPro server motivated by CAPRI. Proteins 2017, 85, 435-444, https://doi.org/10.1002/prot.25219.

33. Kozakov, D.; Hall, D.R.; Xia, B.; Porter, K.A.; Padhorny, D.; Yueh, C.; Beglov, D.; Vajda, S. The ClusPro Web Server for Protein-Protein Docking. Nat. Protoc. 2017, 12, 255-278, https://doi.org/10.1038/nprot.2016.169.

34. Schneidman-Duhovny, D.; Inbar, Y.; Nussinov, R.; Wolfson, H.J. PatchDock and SymmDock: Servers for Rigid and Symmetric Docking. Nucleic. Acids. Res. 2005, 33,W363-367.

35. Van Zundert, G.C.P.; Rodrigues, J.P.G.L.M.; Trellet, M.; Schmitz, C.; Kastritis, P.L.; Karaca, E.; Melquiond, A.S.J.; Van Dijk, M.; De Vries, S.J.; Bonvin, A.M.J.J. The HADDOCK2.2 Web Server: UserFriendly Integrative Modeling of Biomolecular Complexes. J. Mol. Biol. 2016, 428, 720-725, https://doi.org/10.1016/j.jmb.2015.09.014.

36. Ritchie, D.W.; Kemp, G.J.L. Protein Docking Using Spherical Polar Fourier Correlations. Proteins Struct. Funct. Genet. 2000, 39, 178-194, https://doi.org/10.1002/(SICI)1097-0134(20000501)39:2<178::AIDPROT8>3.0.CO;2-6.

37. Chen, R.; Li, L.; Weng, Z. ZDOCK: An Initial-Stage Protein-Docking Algorithm. Proteins Struct. Funct. Genet. 2003, 52, 80-87, https://doi.org/10.1002/prot.10389. 
38. Katebi, A.R.; Kloczkowski, A.; Jernigan, R.L. Structural Interpretation of Protein-Protein Interaction Network. BMC. Struct. Biol. 2010, 10, S1-S4, https://doi.org/10.1186/1472-6807-10-S1-S4.

39. Zhang, C.; Vasmatzis, G.; Cornette, J.L.; DeLisi, C. Determination of Atomic Desolvation Energies from the Structures of Crystallized Proteins. J. Mol. Biol. 1997, 267, 707-26, https://doi.org/10.1006/jmbi.1996.0859.

40. Spiliotopoulos, D.; Kastritis, P.L.; Melquiond, A.S.J.; Bonvin, A.M.J.J.; Musco, G.; Rocchia, W.; Spitaleri, A. DMM-PBSA: A New HADDOCK Scoring Function for Protein-Peptide Docking. Front. Mol. Biosci. 2016, 3, https://doi.org/10.3389/fmolb.2016.00046

41. Xue, L.C.; Rodrigues, J.P.; Kastritis, P.L.; Bonvin, A.M.; Vangone, A. PRODIGY: A Web Server for Predicting the Binding Affinity of Protein-Protein Complexes. Bioinformatics 2016, 32, 3676-3678, https://doi.org/10.1093/bioinformatics/btw514.

42. Vangone, A.; Bonvin, A.M.J.J. Contacts-Based Prediction of Binding Affinity in Protein-Protein Complexes. Elife 2015, 4, https://doi.org/10.7554/eLife.07454.

43. Pettersen, E.F.; Goddard, T.D.; Huang, C.C.; Couch, G.S.; Greenblatt, D.M.; Meng, E.C.; Ferrin, T.E. UCSF Chimera - A Visualization System for Exploratory Research and Analysis. J. Comput. Chem. 2004, 25, 16051612.

44. Laskowski, R.A.; Swindells, M.B. LigPlot+: Multiple Ligand-Protein Interaction Diagrams for Drug Discovery. J. Chem. Inf. Model 2011, 51, 2778-2786, https://doi.org/10.1021/ci200227u.

45. Khan, M.K.A.; Akhtar, S.; Arif, J.M. Development of In Silico Protocols to Predict Structural Insights into the Metabolic Activation Pathways of Xenobiotics. Interdiscip. Sci. Comput. Life Sci. 2018, 10, 329-345, https://doi.org/10.1007/s12539-017-0237-4.

46. Khan, M.; Khan, M.A.; Ansari, I.; Arif, J. Dietary Phytochemicals as Potent Chemotherapeutic Agents against Breast Cancer: Inhibition of NF-KB Pathway via Molecular Interactions in Rel Homology Domain of Its Precursor Protein P105. Pharmacogn. Mag. 2013, 9, 51-57, https://doi.org/10.4103/09731296.108140.

47. Khan, M.; Akhtar, S.; Arif, J.M. Structural Insight into the Mechanism of Dibenzo[a,1]pyrene and Benzo[a]pyrene-Mediated Cell Proliferation Using Molecular Docking Simulations. Interdiscip. Sci. Comput. Life Sci. 2018, 10, 653-673, https://doi.org/10.1007/s12539-017-0226-7.

48. Rehman, A.; Akhtar, S.; Siddiqui, M.H.; Sayeed, U.; Ahmad, S.S.; Arif, J.M.; Khan, M.K.A. Identification of Potential Leads against 4-Hydroxytetrahydrodipicolinate Synthase from Mycobacterium Tuberculosis. Bioinformation. 2016, 12, 400-407, https://doi.org/10.6026/97320630012400.

49. Mariani, V.; Biasini, M.; Barbato, A.; Schwede, T. IDDT: A Local Superposition-Free Score for Comparing Protein Structures and Models Using Distance Difference Tests. Bioinformatics. 2013, 29, 2722-2728.

50. Agrawal, P.; Singh, H.; Srivastava, H.K.; Singh, S.; Kishore, G.; Raghava, G.P.S. Benchmarking of Different Molecular Docking Methods for Protein-Peptide Docking. BMC Bioinformatics 2019, 19, https://doi.org/10.1186/s12859-018-2449-y.

51. Chen, R.; Weng, Z. Docking Unbound Proteins Using Shape Complementarity, Desolvation, and Electrostatics. Proteins Struct. Funct. Genet. 2002, 47, 281-294, https://doi.org/10.1002/prot.10092.

52. Geng, C.; Narasimhan, S.; Rodrigues, J.P.G.L.M.; Bonvin, A.M.J.J. Information-Driven, Ensemble Flexible Peptide Docking Using HADDOCK. Methods. Mol. Biol. 2017, 1561, 109-138, https://doi.org/10.1007/9781-4939-6798-8_8.

53. Basit, A.; Ali, T.; Rehman, S.U. Truncated Human Angiotensin Converting Enzyme 2; a Potential Inhibitor of SARS-CoV-2 Spike Glycoprotein and Potent COVID-19 Therapeutic Agent. J. Biomol. Struct. Dyn. 2020, 1-10, https://doi.org/10.1080/07391102.2020.1768150.

54. Ramírez, D.; Caballero, J. Is It Reliable to Use Common Molecular Docking Methods for Comparing the Binding Affinities of Enantiomer Pairs for Their Protein Target? Int. J. Mol. Sci. 2016, 17, https://doi.org/10.3390/ijms17040525.

55. Kastritis, P.L.; Bonvin, A.M.J.J. Are Scoring Functions in Protein-Protein Docking Ready to Predict Interactomes? Clues from a Novel Binding Affinity Benchmark. J. Proteome Res. 2010, 9, 2216-2225, https://doi.org/10.1021/pr9009854.

56. Du, L.; He, Y.; Zhou, Y.; Liu, S.; Zheng, B.J.; Jiang, S. The Spike Protein of SARS-CoV - A Target for Vaccine and Therapeutic Development. Nat. Rev. Microbiol. 2009, 7, 226-236, https://doi.org/10.1038/nrmicro2090.

57. Wang, Q.; Wong, G.; Lu, G.; Yan, J.; Gao, G.F. MERS-CoV Spike Protein: Targets for Vaccines and Therapeutics. Antiviral Res. 2016, 133, 165-167, https://doi.org/10.1016/j.antiviral.2016.07.015.

58. Berg, M.K.; Yu, Q.; Salvador, C.E.; Melani, I.; Kitayama, S. Mandated Bacillus Calmette-Guérin (BCG) Vaccination Predicts Flattened Curves for the Spread of COVID-19. Sci. Adv. 2020, 6, http://doi.org/10.1126/sciadv.abc1463. 


\section{Supplementary data}

Table S1. Interface residues between S1-CTD and ACE2 using the Hex tool. S1-CTD

\begin{tabular}{l|l}
\multicolumn{1}{c|}{ S1-CTD } & \multicolumn{1}{c}{ ACE2 } \\
\hline ALA475 (3) & \multicolumn{1}{|c}{ GLN24, SER19, THR27 } \\
\hline GLY476 (2) & GLN24, SER19 \\
\hline ASN487 (3) & PHE28, GLN24, TYR83 \\
\hline PHE456 (3) & ASP30, LYS31, THR27 \\
\hline TYR473 & THR27 \\
\hline ASN489 (5) & GLN24, TYR83, LYS31, THR27, PHE28 \\
\hline LYS417 (2) & ASP30, HIS34 \\
\hline LEU455 (3) & HIS34, ASP30, LYS31 \\
\hline GLU484 & LYS31 \\
\hline PHE486 (2) & LEU79, MET82 \\
\hline PHE490 & LYS31 \\
\hline GLN493 (3) & HIS34, GLU35, LYS31 \\
\hline TYR505 (5) & ARG393, GLY354, ALA386, LYS353, GLU37 \\
\hline TYR449 (2) & GLN42, ASP38 \\
\hline GLY496 (2) & LYS353, ASP38 \\
\hline GLN498 (5) & ASP38, LEU45, GLN42, LYS353, TYR41 \\
\hline THR500 (7) & LEU45, LYS353, ASP355, ARG357, TYR41, ASN330, GLY354 \\
\hline TSN501 (4) & TYR41, LYS353, ASP355, GLY354 \\
\hline LEU453 (3) & HIS34 \\
\hline TYR502 (3) & ASIS34, ASP30, LYS31 \\
\hline
\end{tabular}

$\$$ Number in parenthesis denotes number of times it is interacting with host residues.

E36 is missing in ACE2 as per the data reported [15].

Table S2. Interface residues between S1-CTD and IgG using the Hex tool.

\begin{tabular}{l|l}
\multicolumn{1}{c|}{ S1-CTD } & \multicolumn{1}{c}{ IgG $^{\#}$} \\
\hline ALA475 (2) & HIS81, LYS20 \\
\hline ASN487 & LYS20 \\
\hline PHE456 (6) & SER22, HIS81, THR79, SER8, CYS23, LYS24 \\
\hline TYR473 (2) & SER77, ASP74 \\
\hline ASN489 (5) & HIS81, SER22, GLU11, ILE21, LYS20 \\
\hline LYS417 (9) & SER26, GLN4, SER78, THR79, SER77, CYS23, ALA25, LYS24, GLN6 \\
\hline LEU455 (8) & THR79, SER22, GLN6, GLN7, GLY9, LYS24, SER8, CYS23 \\
\hline GLU484 & GLU11 \\
\hline PHE486 (3) & SER18, GLN83, LYS20 \\
\hline GLN493 (7) & GLY113, GLU11, THR114, PRO10, SER8, GLY9, GLN7, \\
\hline TYR505 (8) & SER42, VAL109, LEU5, ARG45, GLY111, ALA112, SER43 (L), TRP110 \\
\hline TYR449 (6) & PRO156, THR158, PRO207, PRO10, VAL157, THR115 \\
\hline GLY496 & GLY41 (L) \\
\hline GLN498 (2) & GLY41 (L), PRO40 (L) \\
\hline THR500 (6) & SER42 (L), ASP165 (L), LYS39 (L), SER168 (L), PRO40 (L), GLY41 (L) \\
\hline ASN501 (4) & PRO40 (L), SER43 (L), SER42 (L), GLY41 (L), \\
\hline TYR453 (3) & GLN7, SER8, GLN6 \\
\hline LEU455 (8) & THR79, SER22, GLN6, GLN7, GLY9, LYS24, SER8, CYS23 \\
\hline TYR502 (2) & SER42, ARG45
\end{tabular}

\#IgG- Fab fragment of IgG2a LA5.

${ }^{\$}$ Number in parenthesis denotes the number of times it is interacting with host residues.

' $\mathrm{L}$ ' in parenthesis denotes the light chain of $\mathrm{Ab}$.

GLY476 and PHE490 residues are missing in S1-CTD as per the data reported by [15].

Table S3. Interface residues between S-CTD and IgA using the Hex tool.

\begin{tabular}{l|l}
\multicolumn{1}{c|}{ S-CTD } & \multicolumn{1}{|c}{ IgA } \\
\hline PHE456 & LYS217 \\
\hline ASN489 (2) & ASP219, LYS217 \\
\hline LYS417 & LYS212 \\
\hline LEU455 (3) & LYS212, ASN210, LYS217 \\
\hline GLU484 (5) & ASP219, SER167, ASN208, ASN166, ILE206 \\
\hline PHE490 (6) & ASP219, ASN208, LYS217, GLY168, ASN166, SER167 \\
\hline GLN493 (10) & THR162, LYS217, VAL163, GLY168, ASN210, VAL209, ASN208, ASP219, SER164, SER167 \\
\hline TYR505 (6) & VAL161, PRO213, GLU159, LEU119, THR162, PRO160 \\
\hline TYR449 (11) & $\begin{array}{l}\text { HIS175, LEU170, THR176, VAL163, SER191, THR171, VAL174, GLY168, PHE177, TRP165, } \\
\text { SER164 }\end{array}$
\end{tabular}




\begin{tabular}{l|l}
\multicolumn{1}{c|}{ S-CTD } & \\
\hline GLY496(3) & VAL163, THR162, THR176 \\
\hline GLN498 (4) & PHE177, THR176, PRO178, HIS175 \\
\hline THR500 & PRO178 \\
\hline TYR453 (3) & THR102, ASN210, LYS212 \\
\hline LEU455 (3) & LYS212, ASN210, LYS217 \\
\hline TYR502 (2) & VAL93, TYR95
\end{tabular}

$\$$ Number in parenthesis denotes the number of times it is interacting with host residues.

ALA475, GLY476, ASN487, TYR473, PHE486, ASN501 residues are missing in S1-CTD as per the data reported [15].

Table S4. Interface residues between E-protein and MPP5 using the Hex tool.

\begin{tabular}{l|l}
\multicolumn{1}{c}{ E-protein } & \multicolumn{1}{c}{ MPP5 } \\
\hline GLU8 (11) & \multicolumn{1}{c}{ } \\
& LYE265, GLY268, LYS285, VAL284, LEU267, ALA288, PHE266, GLY287, \\
\hline GLY10 & ILE265 \\
\hline THR11 (3) & PRO266, ILE265, ASP264 \\
\hline LEU12 (3) & ASP264, PRO266, ILE265 \\
\hline ILE13 & PRO266 \\
\hline VAL14 (3) & GLY268, PRO266, VAL284 \\
\hline ASN15 (3) & PRO266, PHE318, SER322 \\
\hline SER16 (2) & PHE318, PRO266 \\
\hline VAL17 (2) & THR270, PHE318 \\
\hline LEU18 (7) & ALA269, PRO266, GLY268, THR270, PHE318, VAL217, ARG272 \\
\hline LEU19 (8) & VAL314, VAL317, GLU316, ASN315, THR270, ASP319, PHE318, VAL271 \\
\hline LEU21 (5) & ARG272, ARG282, THR270, SER281, VAL271, \\
\hline ALA22 (4) & ARG272, ASN273, VAL271, VAL314 \\
\hline PHE23 (3) & ASP313, VAL314, ASN315 \\
\hline VAL25 (4) & ASN273, ARG272, SER281, VAL271 \\
\hline PHE26 (6) & ARG272, ASN273, ASP313, MET275, VAL314, GLU274 \\
\hline VAL29 (2) & MET275, ASN273 \\
&
\end{tabular}

Table S5. Interface residues between E-protein and IgG using Hex tool.

\begin{tabular}{l|l}
\multicolumn{1}{c|}{ E-protein } & \multicolumn{1}{c}{ IgG $^{\#}$} \\
\hline GLU8 (3) & GLN44, GLY43, PRO42 \\
\hline GLY10 & LEU177 \\
\hline THR11 (3) & VAL176, LEU177, PRO42 \\
\hline LEU12 (9) & PRO42, SER89, ARG41, TYR182, THR117, LEU177, VAL116, SER92, VAL118 \\
\hline ILE13 (6) & TYR182, LEU177, ALA175, GLU155, VAL176, PRO42, \\
\hline VAL14 (2) & VAL94, PRO42 \\
\hline ASN15 (10) & THR115, THR114, VAL94, PRO42, THR117, VAL116, ALA93, GLN40, ARG41, SER92, \\
\hline SER16 (4) & TYR182, VAL94, THR115, GLU155, \\
\hline VAL17 (5) & GLY41 (L), PRO174, ASP165 (L), GLU155, ALA175 \\
\hline LEU18 (10) & SER42 (L), PRO42, GLN38 (L), GLN40, TYR96, VAL94, GLY41 (L), THR115, PRO40 (L), ALA112 \\
\hline LEU19 (8) & VAL94, ALA112, GLY113, GLY41 (L), THR155, TYR95, THR114, TYR96 \\
\hline LEU21 (5) & SER42 (L), GLY41 (L), LYS39 (L), ASP165 (L), PRO40 (L) \\
\hline ALA22 (5) & SER43 (L), GLY41 (L), GLY113, SER42 (L), ALA112 \\
\hline PHE23 (5) & GLY113, GLY41(L), PRO10, ALA112, PRO156, \\
\hline VAL25 (2) & GLY41 (L), SER42 (L) \\
\hline PHE26 (6) & LEU5, ALA112, GLY111, TRP110, GLN4, GLN6
\end{tabular}

${ }^{\#} \mathrm{IgG}-\mathrm{Fab}$ fragment of IgG2a LA5.

$\$$ Number in parenthesis denotes the number of times it is interacting with host residues.

' $\mathrm{L}$ ' in parenthesis denotes light chain.

VAL29 is missing in E as per the data showing in E-protein and MPP5 interactions.

Table S6. Interface residues between E-protein and IgA using the Hex tool.

E-protein GLU8 (7)

GLY10 (7)

THR11 (7)

LEU12 (12)
IgA

THR162, PRO160, GLY47 (L), VAL163, VAL161, THR176, GLY42,

PRO160, LEU119, GLU159, ALA9, THR118, VAL93, VAL120,

LEU119, GLN116, GLU159, PRO160, GLY47 (L), TYR95, VAL93

VAL120, GLY42, VAL93, TYR187, GLN39, PRO41, ALA40, THR121, GLU159, ALA92, THR91,

LEU119

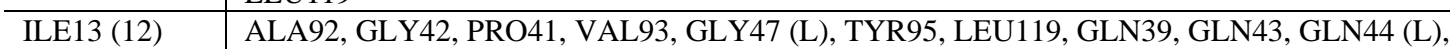
ALA40, GLN48 (L)

VAL14 (5) $\quad$ GLU171 (L), GLY47 (L), SER46 (L), PRO41, GLY42 


\begin{tabular}{l|l}
\multicolumn{1}{c|}{ E-protein } & \multicolumn{1}{c}{ IgA } \\
\hline ASN15 (5) & GLN43, GLY42, PRO41, ALA40, ALA179 \\
\hline SER16 (6) & GLY44, GLN39, PRO41, ALA40, GLY42, GLN43 \\
\hline VAL17 (8) & GLY47 (L), GLU171 (L), LYS109 (L), SER46 (L), GLY42, LYS45 (L), VAL91 (L), GLN43, \\
\hline LEU18 (5) & ARG148 (L), VAL169 (L), THR170 (L), GLU171 (L), PRO178 \\
\hline LEU19 (2) & GLY42, ARG48 (L) \\
\hline LEU21 (10) & $\begin{array}{l}\text { GLU171 (L), ARG148 (L), THR170 (L), LYS109 (L), GLN172 (L), ASP11 (L), VAL110 (L), VAL89 } \\
\text { (L), TYR179 (L), SER10 (L) }\end{array}$ \\
\hline ALA22 (4) & LYS109 (L), SER10 (L), ARG148 (L), GLU149 (L) \\
\hline PHE23 (5) & ARG148 (L), SER10 (L), LEU11 (L), ASP9 (L), LYS109 (L) \\
\hline VAL25 (9) & $\begin{array}{l}\text { ALA12 (L), SER10 (L), PRO147 (L), TYR146 (L), ARG148 (L), GLU149 (L), TYR179 (L), LEU11 } \\
\text { (L), ASP111 (L) }\end{array}$ \\
\hline PHE26 (2) & GLU149 (L), SER10 (L) \\
\hline VAL29 & GLU149 (L) \\
'Number in parenthesis denotes the number of times it is interacting with host residues. \\
'L in parenthesis denotes light chain.
\end{tabular}

